\title{
Connections between masserie and historical roads system in Apulia
}

\author{
Lucia P. Caliandro, ${ }^{1}$ Rosa V. Loisi, ${ }^{2}$ Pasquale Dal Sasso² \\ ${ }^{1}$ Department of Agricultural Sciences, Food and Environment, University of Foggia; \\ ${ }^{2}$ Department of Agro-Environmental and Territorial Science, University of Bari, Italy
}

\begin{abstract}
A precise category of Apulian farmsteads, known as masserie, is a significant example of rural buildings featuring relevant architectural and landscape characteristics. Their territorial distribution is diversified and often depend on the close relationship between the building and its adjacent agricultural lot. Moreover, owing to their specific role in overseeing the territory and asserting land tenure rights, Apulian masserie distribution may have genetic origins influenced by other elements, too. The aim of this work is to investigate the existing relationships between masserie and historic roads crossing the Apulia region (Roman roads and sheep's paths called tratturi), considering both their mutual distance and the individual rural buildings importance. Overlay mapping procedures allow to quantify the amount of masserie falling within the catchment areas of the aforementioned historical roads, while historical and territorial in-depth analysis helped to identify those elements characterising the most interesting masserie from cultural and architectural points of view. The research provided interesting qualitative and quantitative information on the existing rela-
\end{abstract}

Correspondence: Lucia Patrizia Caliandro, Department of Agricultural Sciences, Food and Environment (SAFE), University of Foggia, via Napoli 25, 71100 Foggia, Italy.

Mobile: +39.339 .5877637 - Fax: +39.080 .5442962 .

E-mail: lucia.caliandro@unifg.it

Key words: consular roads, sheep's paths, farmhouses, integrated recovery, geographic information system.

Contributions: the authors contributed equally.

Conflict of interests: the authors declare no potential conflict of interests.

Conference presentation: part of this paper was presented at the $10^{\text {th }}$ Conference of the Italian Society of Agricultural Engineering: Horizons in agricultural, forestry and biosystems engineering, 2013 September 8-12, Viterbo, Italy.

Received for publication: 6 December 2013.

Accepted for publication: 29 March 2014.

(C) Copyright L.P. Caliandro et al., 2014

Licensee PAGEPress, Italy

Journal of Agricultural Engineering 2014; XLV:224

doi:10.4081/jae.2014.224

This article is distributed under the terms of the Creative Commons Attribution Noncommercial License (by-nc 3.0) which permits any noncommercial use, distribution, and reproduction in any medium, provided the original author(s) and source are credited. tions between these assets, leading to further considerations on the possibility to enhance them through the promotion of their integrated recovery.

\section{Introduction and objectives}

Growing demand for rural and cultural tourism contributed to enhance the open territories.

In this context, studies were carried out aimed at recognising elements of historical and cultural importance and identifying structural invariants to be interpreted as strength and starting points in the rural territory enhancement (Dal Sasso and Caliandro, 2010).

The knowledge of territorial endogenous resources provides information for its preservation and encourages promoting cases consistent with other socio-economic aspects belonging to the territory, in the perspective of its environmentally sustainable development.

According to the above, current researches highlight, among other aspects, the need to rediscover and re-evaluate the identity and the endogenous resources of specific places, to dedicate them to multifunctional reuse associated with new development opportunities, in accordance with policies of protection, conservation and enhancement of the environment and its socio-economic and cultural factors (Pašakarnis and Maliene, 2010).

Recent European Community policies, on the other hand, promote the above, defining the priority themes to be pursued to restore the historical and balanced connection between human activities and territory (European Commission, 2006), as already highlighted in the European Conference on Rural Development (Salzburg, 12-14 November 2003).

Furthermore, the European regulatory framework recognises that cultural and architectural heritage plays a crucial role in defining and achieving rural sustainable development, as it is seen as an important component of quality of life and social well being (European Commission, 1998; Council of Europe, 2005), likewise to what has been analysed in purely urban contexts (Tweed and Sutherland, 2007). It's a unique and non-renewable resource, both in urban and extraurban areas, due to its stratification, historical characterisation, and intrinsic stylistic-architectural value (Hassler et al., 2002).

The detection and knowledge of cultural and architectural heritage keeps the memory of the signs alive, characterising the area where it is located, and it is intended both for its own intrinsic aspects, and if analysed in relation to the territorial context and to the presence of infrastructures. Those are indeed factors that have often influenced the initial development of the settlements, as already showed in previous research carried out in various parts of the world (Hudson, 1975; Spooner, 2005; Jurick, 2006).

Therefore, architectural and cultural heritage (Lynch, 1960; Caliandro and Dal Sasso, 2012) is vital in awakening the sense of belonging of a place, in contributing to give historical-landscape identity to a place, in defining the landscape image to which it belongs, as 
well as in reconstructing both the socio-economic past of the ancient production sites and the building techniques of valuable rural buildings (Council of Europe, 2000; Hassler et al., 2002; Van der Vaat, 2005; Dal Sasso and Caliandro, 2010).

Among the characterising assets of historical and cultural heritage in the Apulian rural territory there are the masserie (as this precise category of Apulian farmsteads is known in Italian), the most significant architectural emergencies in rural constructions. They are considered as symbols of the landowner middle class and emblem of a strong relationship between shape and function, cultivation and agricultural firm.

Indeed, the historical road network is the conceptual and physical medium by which landscape, environmental and cultural resources are linked, contributing to add value to the whole territory.

In particular, in the specific study case, the tracks of the historic viability, existing or recognisable on the territory, constitute the physical memory both of the connections between the capital of the Roman Empire with its different regions (consular ways), and the history of the sheep moving (sheep's paths).

In the light of such considerations, this study aim is to identify connections and interrelations between the masserie and the historical road system, i.e. territorial links existing between the most relevant architectural emergencies of the peasant culture and the most important territorial historical infrastructure. The study was carried out on a sample area of the Apulia region, in the province of Taranto, after a preliminary analysis of the regional context.

\section{Materials and methods}

\section{Materials}

Apulia region is characterised by a relevant presence of masserie, scattered in the whole territory, that embody the architectural symbol of peasant culture and the greatest expression of rural building, typical of the medieval age till the end of the XIX century.

The term masseria between the XIII century and the first half of the $\mathrm{XV}$ century referred to a variety of firms dedicated to livestock and cereal-pastoral purpose, but it also indicated the peasant house together with the enclosed cultivated land. In particular, the cereal-pastoral vocation is typical of the royal masserie of the Angevin-Suabian period that were State proprieties and symbols of the central power engagement in the sector of the agricultural product commercialisation. Between the XVI and the XVII century the Apulian masseria, integrated in a still typically feudal economic system, had a decisive role not only as an element characterising the territory of the Apulia region, but also as an essential means for the provision of the Capital of the Kingdom of Naples.

Starting from the XVIII century, the agricultural and land reform of Charles III Borbone led to an intense land tenure fragmentation. It was then possible to assist to a remarkable spread of modern and contemporary aged masserie dedicated to livestock and olive oil production (Licinio, 1981).

Surrounded as they were by huge cultivated lands, the masserie then represented the centre of production and organisation of rural work (Calderazzi, 1989). They offered valuable intrinsic historic-architectural features that are also integrated in rural landscape of great suggestion and identification.

Since each farmhouse has its own features due to the social, economic and agricultural reality of the territory to which it belongs, there are no recurrent building techniques but only improvements or differences between one another which stress their identity. This aspect represents the real value of the masserie as being tout court cultural assets, not only limited to peasant world (Dal Sasso et al., 2009).

In previous studies of the Department of Agro-Environmental and Territorial Sciences (DISAAT), the census of the masserie has been carried out, through the use of the ArcGis software. From this study it comes out that the amount of historic masserie which have been created since the medieval age until the end of $800 \mathrm{~s}$, is of about 5600 units, as detected on the base of the cartography of the Geographic Military Institute (Istituto Geografico Militare, IGM) in scale 1:50,000, drawn up in the 70's (Dal Sasso et al., 2010).

About the $10 \%$ of these masserie no longer exists, while about the $20 \%$ of them is neglected, as highlighted by both on-site inspections and map surveys carried out through the use of ortho-photographs produced by Apulia Region in 2006.

About 3000 of the still existing masserie present relevant historicalarchitectural features and for this reason they were recognised as assets of the regional cultural heritage. They are so identified in the 2010 Cultural Heritage Chart, produced in scale 1:150,000 by the Apulian Regional Administration for the draft of the new Regional Landscape Plan (Piano Paesaggistico Territoriale Regionale or PPTR) (Figure 1A).

The historical routes crossing the regional territory that have been taken into consideration in this study are the Roman consular roads and the tratturi (as the sheep's paths are known in Italian) (Figure 1B and C) (Tragni, 1986; Palasciano, 1999).

The consular roads (Ciacio, 1986), mostly replaced by other arterial roads or hidden by cultivated fields, are still present even if for short stretches, with their original paved area protected, confirming their use until the centuries XVIII-XIX. They still represent a notable functional and structural example, and contribute to the interpretation of some historical stratifications that characterise the territory.

Among the 29 Roman roads spreading from Rome to the rest of Italy, the Appia road and the Trajan road are those crossing the Apulian territory (Figure 1B) (Ciacio, 1986).

In the Apulian Territory, the Trajan road extended for about 505 kilometres, while the Appia Road was about 194 kilometres long.

Indeed, the Appia road was built in stages, as the Roman conquest of new territories expanded. Moreover, from the IV to the II centuries before Christ, the Appula (Apulian) road system represented the main path for the commercial exchanges with Greece and the East Mediterranean (Ciacio, 1986).

Very little is left of such developed road network, after the XVIII century, because its archaeological traces have been destroyed and those paths, which were included in the major routes of the Imperial Age, are nowadays still used and have been rearranged during the centuries (Cippone, 1993).

In this study, for the tracks representation has been adopted the historical cartography (Otranto, 2007) which reproduces Giovanni Antonio Rizzi Zannoni original map, drawn for the Naples reign and dating back to the last twenty years of the XVIII century.

The sheep's paths (Aromatario, 1986) (Figure 1C), deserted or substituted by the ordinary road system in some stretches, nowadays still constitute essential elements of territorial organisation and undoubtedly a symbol of agro-pastoral civilization (Ministero dell'Ambiente, 2004).

Those communication routes were mainly used for the transhumance of the cattle, in particular the ovine one, that allowed the transfer out of the coastal lands to the internal ones and so it should ensure food (green roads) and resting places (stations, jazzi, hunting lodges, etc.) for the cattle. At the beginning of the summertime herds and sheep were pushed towards the mountains, in autumn they were brought back to the plain where they spent the winter trough specific grassy ways called calles pubblicae, only travelable under the payment of a duty to the State. 
For a long time the sheep's paths have then been linking roads between the Abruzzo and Molise Appennine pasture and the Apulian plains, so including wide territories of central and southern Italy and representing the core of a fundamental commercial activity for all the different populations lived in Southern Italy, from the Sanniti to the two Sicilies Kingdom (Ministero dell'Ambiente, 2004).

As deduced by Emperors Teodosio and Giustiniano Codes, it's known that these roads were called tractoria, from which the term tratturi derived, that is still in use.

Their economic role is already present in Roman times. Their use was subdued to a tax payment, the publicum vectigal, which varied according to the animals' number and weight.

In the Middle Ages Alfonso I d'Aragona established the Regia dogana per la mena delle pecore in Puglia, the institution which administered the sheep's paths system and was in charge of collecting the Royal tax by the herds owners who used the State property lands for cattle-rearing.

The sheep's paths golden age lasted till 1806, when Giuseppe Bonaparte abolished the Regia Dogana (Licinio, 1981; Colapietra, 1985; Tragni, 1986; Palasciano, 1999).

The main sheep's paths were linked by a series of branches and little sheep's paths; the width of the first was fixed in 60 steps or Neapolitan steps, corresponding to 111.11 metres; the second has a 30 steps ( 55.55 metres) width and the little sheep's paths, which linked the sheep's paths and gave access to the mountain pastures and locations, has a width that varied from 20.15 (37.31 meters) to 10 steps (18.52 meters) (Palasciano, 1999; Otranto, 2007).

According to a list compiled in 1912 (Italian Regulation, 1912), the sheep's paths entire extension amounted to 2978.29 kilometres for a total of 21,000 hectares included in five regions: Abruzzo, Molise, Apulia, Campania and Basilicata.

As far as the Apulian territory is concerned, the sheep's paths system extends for about 1990 kilometres and crosses the territories of the province of Foggia, where the sheep's paths network is very dense, and the province of Bari, mainly in the pre-Murgia and Murgia area, to become thicken again in the province of Taranto (Figure 1C).

The sheep's paths map adopted in this study was detected by the one reported in the Apulian Territorial Urban Planning/Landscape Map (Piano Urbanistico Territoriale Tematico/Paesaggio or PUTT/P), which is in turn deduced from the Sheep's paths Chart, drawn up in scale 1:50,000 by the Commissary for the reinstatement of the sheep's paths of Foggia in 1959 .

\section{Study area}

The province of Taranto, whose total surface area is of 2421 square kilometres, was chosen as this study area, due to the fact that it is largely affected by the presence of masserie recognised as cultural heritage, reported in the already mentioned Cultural Heritage Chart, produced by the Apulian Regional Administration.

The central area of the province (municipalities of Martina Franca, Grottaglie and Taranto) is crossed by a thick net of sheep's paths and by the historical Appia road. Most of the valuable masserie of the study area dates back to a period variable between the end of the XVIII century and the whole XIX century. Moreover, new forms of rural tourism have been developing in this area. Those are recently aimed at the quality of products and services, and tend to promote the cultural, landscape and environmental peculiarities.

\section{Methodology}

The research work is composed by four phases.

\section{I phase: Masserie census}

In the first phase, starting from previous works results (Dal Sasso et al., 2009; Dal Sasso et al., 2010), the geo-database of all the Apulian masserie has been further implemented in a GIS environment (Arcview 9.3.2 software package), using as cartographic base the IGM map drawn up for Apulia, in the decade 1950-1960, in a 1:25,000 scale.
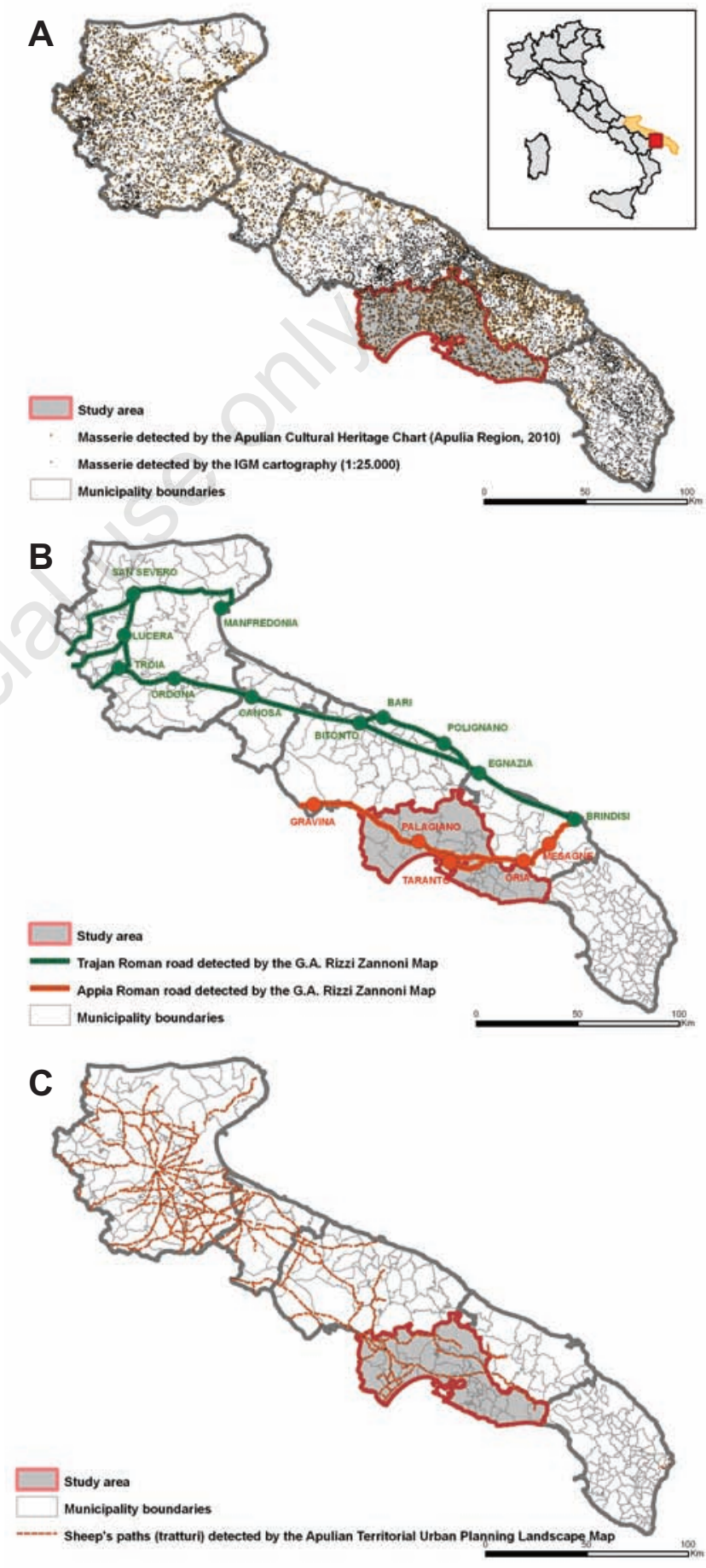

Figure 1. A) Masserie detected by the Geographic Military Institute cartography (scale 1:25,000) and by the Apulian Cultural Heritage Chart; B) Roman consular roads; C) Apulian sheep's path system. 
Later on, an overlapping of the so resulting map with the already mentioned Cultural Heritage Chart (Figure 1A), containing the identification of the valuable masserie, was carried out. This identification in the study area was carried out taking into consideration both the criterions used for the draft of the Cultural Heritage Chart, as reported in the descriptive tables of the new Regional Landscape Plan, and the extrinsic and intrinsic specific features already analysed in previous works, with reference to other assets typologies (Dal Sasso and Caliandro, 2010).

In particular the close connection of the masserie with the surrounding territorial and farming context was assessed.

\section{II phase: Historical paths analysis}

In order to allow the individuation of the historical paths and to proceed with territorial analysis, in this second phase, the raster file related to the historical map of the consular roads, previously mentioned (Otranto, 2007), was geo-referenced in the WGS84 reference system, with the help of the georeferencing tool of the Arcview 9.3 software, produced by Esri (Figure 1B).

Later on, the already mentioned sheep's paths map (Figure 1C) was overlapped on the ortho-photographs produced by Apulia Region in 2006 , in order to verify the correspondence between the historic tracks and the still existing viability.

With the help of the clip tool of the already mentioned software, the attention has been focused on the whole historical paths included in the study area, verifying their current consistency.

\section{III phase: Parameters of correlation between the two systems}

In the third phase correlations between the masserie system and the historical path network in the province of Taranto have been evaluated. At first, the catchment area of the historical road tracks has been identified with the surface of the zones included between the sheep's paths ground area and the distance of $1 \mathrm{~km}$ for each side. It is indeed known that the walk-able distance over a period of half an hour, assuming $0 \%$ slope, is around $2 \mathrm{~km}$. In literature (Dal Sasso et al., 2004), in addition, in a mountain territory the catchment areas result to be equal to 200 metres for side. In the specific study case that distance was set equal to 1 kilometre, as it is considered the most significant in order to verify the inter-visibility between the viability and the masseria. This parameter was considered essential to establish the interconnection between the aforementioned assets. The inter-visibility, in fact, confirms the attraction role of the viability on the rural settlement. The chosen distance can then be probably considered as the identification of a real contiguity relation between the road and the building. With the help of a GIS tool, the so defined catchment area of the historical paths crossing the analysed territory (Appia Roman road and sheep's paths) was built. Subsequently those masserie falling within the aforementioned areas, and related to each path, have been detected (Figure 2).

\section{IV phase: Parameters evaluation}

The last phase led to the quantitative and qualitative evaluation of the masserie set in the historical road system catchment area, as explained in the next paragraph.

\section{Results and discussion}

As a result of the first methodological phase it was detected that in Apulia there are 8470 masserie (Table 1). Among the 6630 still existing ones, about 3000 masserie feature relevant historical-architectural qualities and were recognised as regional cultural heritage assets and surveyed by the Cultural Heritage Chart of the Apulian Regional Administration, published in 2010.

In the whole province of Taranto 1157 masserie were detected, and $52 \%$ of them are recorded in the aforementioned Cultural Heritage Chart (Table 1).

As deduced from Table 2, the masserie of the study area that lie
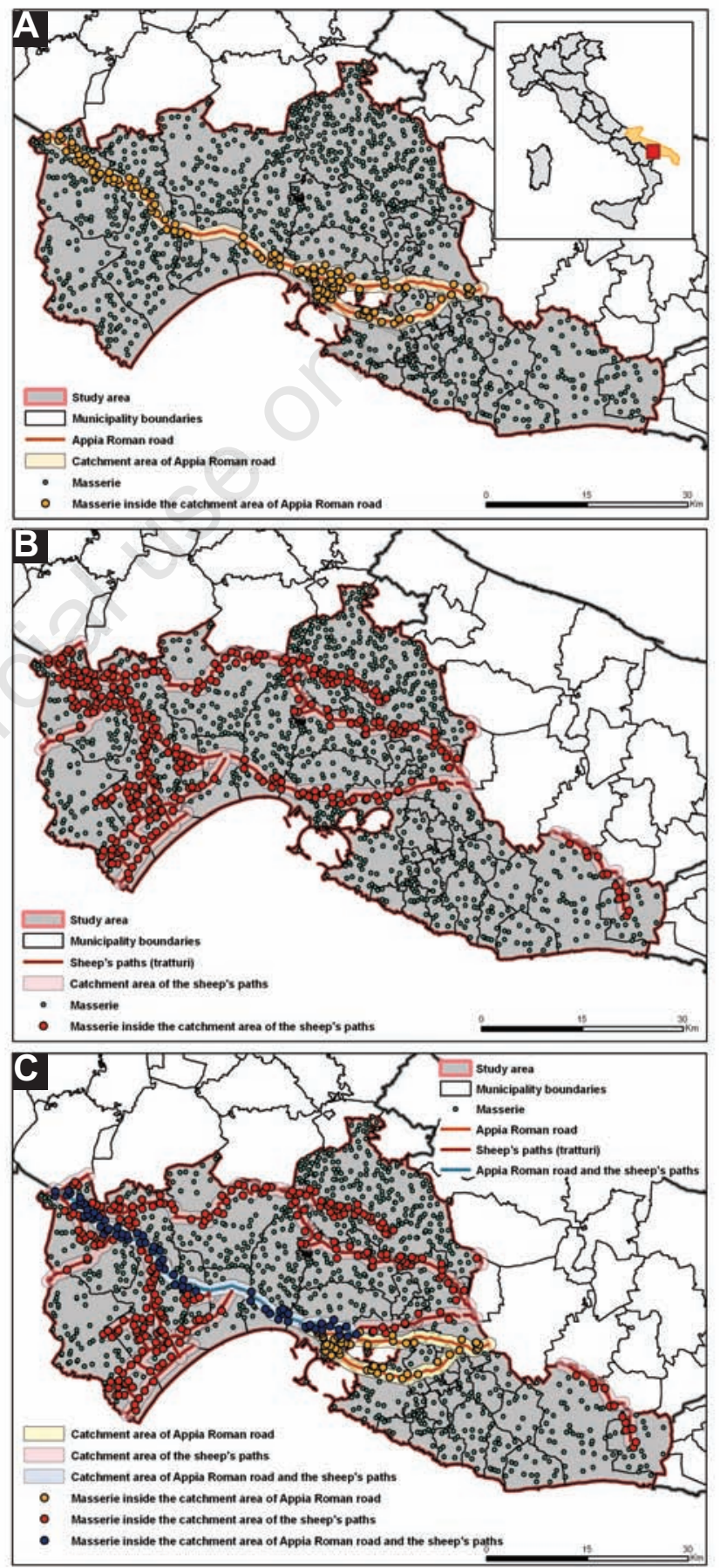

Figure 2. A) Relationships between the Appia Roman consular road and the masserie system; B) Relationships between the sheep's paths and the masserie system; C) Relationships among the Appia Roman consular road, the sheep's paths and the masserie system. 
Table 1. Named masserie detected by the Geographic Military Institute cartography (scale 1:25,000) and by the Apulian Cultural Heritage Chart.

\begin{tabular}{lcccccc}
\hline Province & Foggia & BAT & Bari & Brindisi & Taranto & Lecce Total \\
Masserie detected by IGM cartography & 2587 & 507 & 1820 & 980 & 1157 & 1419 \\
Masserie detected by the Apulian Cultural Heritage Chart & 1144 & 211 & 321 & 539 & 606 & 127 \\
\hline
\end{tabular}

BAT, Barletta-Andria-Trani; IGM, Istituto Geografico Militare (Geographic Military Institute).

Table 2. Data on the relations between the masserie and the historical paths.

\begin{tabular}{|c|c|c|c|c|c|c|c|c|}
\hline $\begin{array}{l}\text { Historical } \\
\text { road } \\
\text { system }\end{array}$ & $\begin{array}{c}\text { Masserie } \\
\text { (N) }\end{array}$ & $\begin{array}{l}\text { Masserie detected / } \\
\text { Provincial farmhouses } \\
\text { (equal to 1157) } \\
(\%)\end{array}$ & $\begin{array}{c}\text { Masserie detected } \\
\text { by the Apulian } \\
\text { Cultural Heritage } \\
\text { Chart }\end{array}$ & $\begin{array}{l}\text { Road } \\
\text { length } \\
\text { (km) }\end{array}$ & $\begin{array}{l}\text { Masserie/km } \\
\text { (N/km) }\end{array}$ & $\begin{array}{l}\text { Catchment } \\
\text { area } \\
\left(\mathrm{km}^{2}\right)\end{array}$ & $\begin{array}{l}\text { Internal density } \\
\text { Masserie detected } \\
\text { inside/ } \\
\text { catchment area } \\
\left(\mathrm{N} / \mathrm{km}^{2}\right)\end{array}$ & $\begin{array}{c}\text { External density } \\
\text { Masserie detected } \\
\text { outside/rest of the } \\
\text { provincial area } \\
\left(\mathrm{N} / \mathrm{km}^{2}\right)\end{array}$ \\
\hline Appia Roman road & 114 & 10 & 41 & 109 & 1.04 & 218 & 0.52 & - \\
\hline Sheep's paths (tratturi) & 314 & 27 & 150 & 306 & 1.02 & 612 & 0.51 & - \\
\hline $\begin{array}{l}\text { Sheep's paths (tratturi) } \\
\text { overlapped with Appia } \\
\text { Roman road }\end{array}$ & 69 & 6 & 25 & 53 & 1.30 & 106 & 0.65 & - \\
\hline Total & $\begin{array}{c}359 \\
(428-69)\end{array}$ & 31 & $\begin{array}{c}166 \\
(191-25)\end{array}$ & $\begin{array}{c}362 \\
(415-53)\end{array}$ & $\begin{array}{c}0.99 \\
(359 / 362)\end{array}$ & $\begin{array}{c}724 \\
(830-106)\end{array}$ & $\begin{array}{c}0.50 \\
(359 / 724)\end{array}$ & $\begin{array}{c}0.46 \\
(778 / 1697)\end{array}$ \\
\hline
\end{tabular}

inside the catchment area of the historical paths are 359 , equal to $31 \%$ of the total amount of the provincial ones. The valuable masserie included in the aforementioned areas are 166.

The importance of the masserie inside those areas is great, if we particularly consider both the fact that the surface of the catchment areas is small if compared to the provincial territorial surface (about the $30 \%$ ) and that the masserie were real landmarks for the internal territories (Fuzio, 1974) and, for this reason, they were built, in general, in places located far from main communication roads and urban centres.

This thesis is confirmed by the comparison between the internal and external density related to the buffer, as deduced from Table 2, where it is shown that the quantitative difference between the two values is still more evident if the single historical paths are separately considered.

The Appia road path has a value of linear correlation to the masserie similar to the one existing between masserie and sheep's paths, as shown in Table 2, where $1.04 \mathrm{farms} / \mathrm{km}$ for the Appia road and 1.02 farms $/ \mathrm{km}$ for the sheep's paths have been detected.

This road, effectively, in different periods of time, was used as a sheep's path in the stretch between the Tratturo Melfi-Castellaneta and the Tratturello Tarantino, for a total length of about 53 kilometres, about the half of its track. Considering this common portion, indeed, it can be noticed that, due to the presence of 69 masserie in the catchment area, their impact value grows to 1.30 in relation to the path length.

The percentage distribution of the masserie placed within the catchment area of the sheep's paths, as showed in Table 2, still represents a considerable amount, particularly considering the great extension of the provincial sheep's paths system.

The sheep's paths counting a massive presence of masserie in their catchment area are the Tratturo Melfi-Castellaneta, the Tratturello Orsanese and the Tratturello Gorgo-Parco (Table 3).

The closeness of several masserie to the aforementioned sheep's paths mainly in these specific cases shows how the agro-pastoral infrastructure had given an input to their location, also considering that, as before highlighted, the sheep's paths had featured their role for many centuries before the presence of the masserie. Also the consular roads
Table 3. Masserie placed within the catchment area of the individual sheep's paths.

\begin{tabular}{lccc} 
Sheep's paths & $\begin{array}{c}\text { Masserie } \\
(\mathbf{N})\end{array}$ & $\begin{array}{c}\text { Road length } \\
(\mathrm{km})\end{array}$ & $\begin{array}{c}\text { Masserie/km } \\
(\mathrm{N} / \mathrm{km})\end{array}$ \\
Melfi-Castellaneta & 30 & 14.8 & 2.02 \\
Santeramo in Colle-Laterza & 24 & 16.2 & 1.48 \\
\hline Martinese & 100 & 92.5 & 1.08 \\
Murge & 11 & 6.8 & 1.61 \\
\hline Tarantino & 52 & 57.8 & 0.90 \\
Orsanese & 30 & 16.9 & 1.77 \\
\hline Quero & 14 & 9.8 & 1.42 \\
Palagiano-Bradano & 27 & 28.6 & 0.94 \\
\hline Pineto & 13 & 17.6 & 0.74 \\
Bernalda-Ginosa-Laterza & 13 & 13.5 & 0.97 \\
\hline Pini & 11 & 8.3 & 1.34 \\
Ferre & 5 & 4.3 & 1.16 \\
\hline Gorgo-Parco & 33 & 18.9 & 1.74 \\
Total & 363 & 306 & - \\
\hline
\end{tabular}

showed their attractiveness but, the disappearing of the tracks during the end of XVIII century and the XIX century, corresponded exactly with the period of the biggest growth and spread of the masserie in Apulia.

Masserie placed in the catchment areas of the sheep's paths located in the north-west side of Taranto present characteristics that differ to those of masserie placed where the Tratturello Gorgo-Parco is located.

The first, like Tafuri farmhouse in the municipality of Castellaneta, are characterised by largely built areas due to the extension of the cultivated lands and the distance from the centres of labour recruiting. They looked like small villages, with peasants' houses grouped around the manor house and the church (Colamonico, 1970).

Masserie placed in the catchment area of the Tratturello Gorgo-Parco 

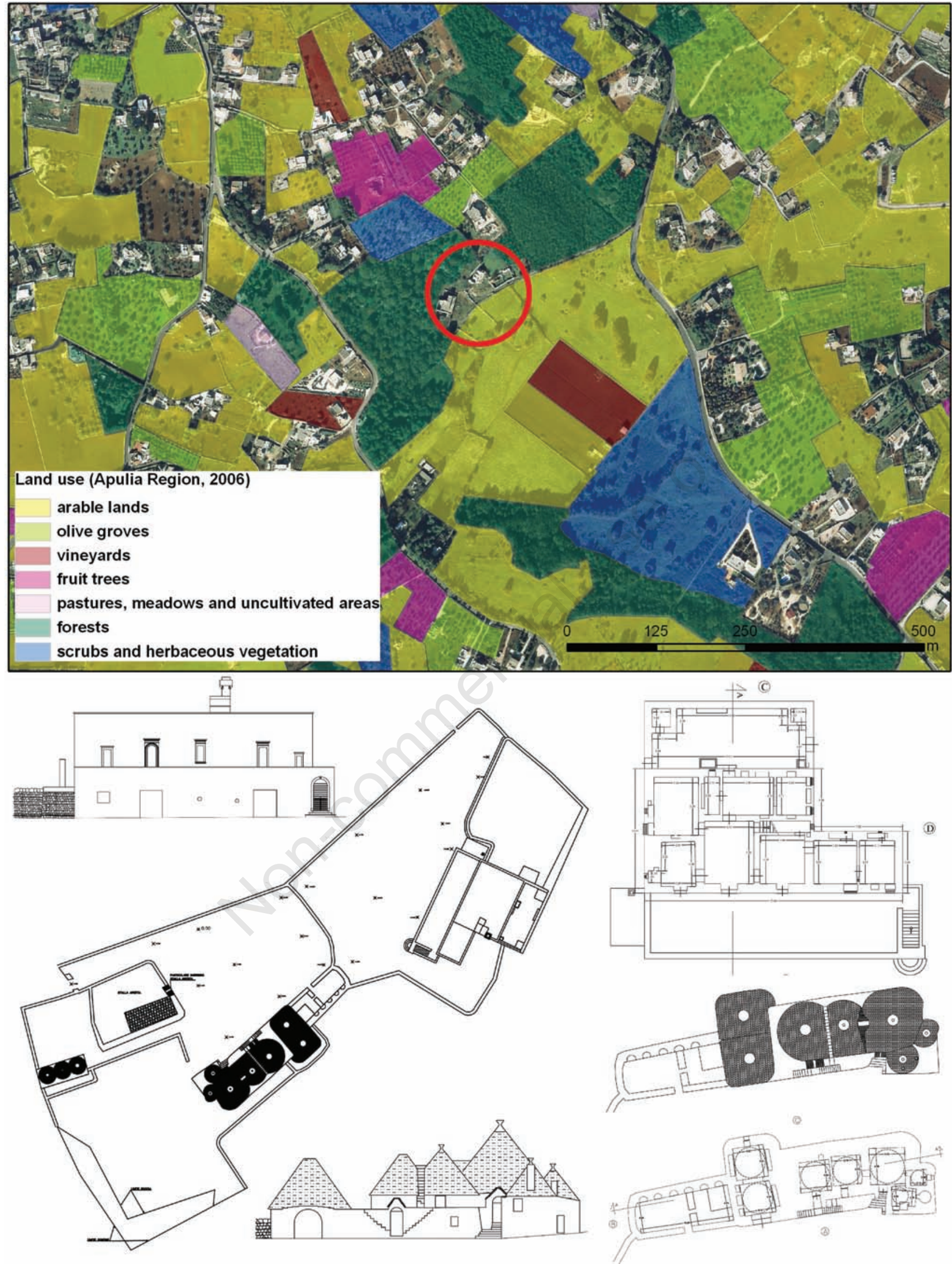

Figure 3. Architectonic survey of a masseria with trulli in Martina Franca countryside. 


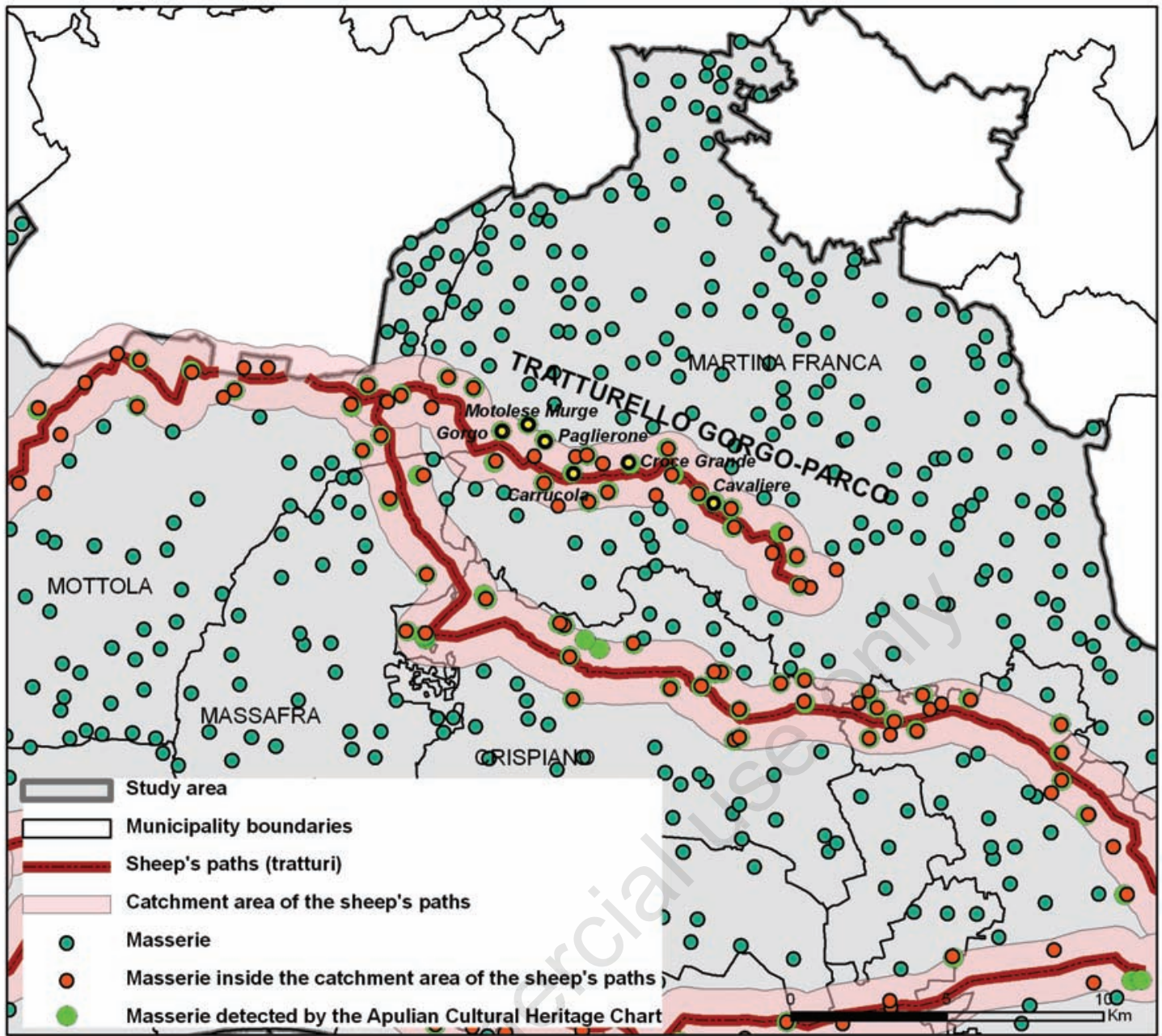

Figure 4. Valuable masserie in the catchment area of Tratturello Gorgo-Parco.

are generally characterised by a two-floor building, the manor house and rural buildings with the typical shape of trullo grouped together, in pair or in line, creating an open yard with the manor house (Figure 3).

Among the most significant examples of this masserie typology within the catchment area of the Tratturello Gorgo-Parco (Figure 4), there are the masserie showed in Figure 5.

Along the Tratturello Martinese, the longest in the province of Taranto, there are stretches presenting a relevant concentration of masserie, particularly near Crispiano-Grottaglie and CastellanetaLaterza, which include on the same path both the masserie typologies above mentioned.

\section{Conclusions}

This research drew a connection between the masserie of a part of the province of Taranto with the tracks of the main historical roads, in order to verify the level of attractiveness that the ones have had on the others. The results clearly showed as the location of the masserie was influenced by the presence mainly of the sheep's paths then of the con- sular roads, especially for the fact that the sheep's paths belong to the rural sector. In the study case the sheep's paths, with its partially existing or almost recognisable tracks, can become a real cultural-historical resource witnessing the old peasant culture, if properly detected and enhanced. On the other hand, the consular roads are today almost totally disappeared, but after a proper activity aimed at recognise them in the territory, they can also be seen as further historic elements characterising the integrated resources system of masserie and sheep's paths, that are the main object of this work.

In perspective of a sustainable development, the investigation of integrated endogenous resources is a key action for a correct use of the territory and for a future development respectful of the environment and the landscape, to be applied for the definition of territorial plans that, far from being only an ideal guide, also constitute practical guidelines for any form of intervention.

In addition, the dimensional and architectural features of most of the masserie located inside the aforementioned catchment areas can promote rural territory development. It can be pursued both through their reuse and restoration, keeping in mind their touristic, didactic, leisure and research reuse destination, and also with the arrangement of not yet reintegrated sheep' paths portions. 

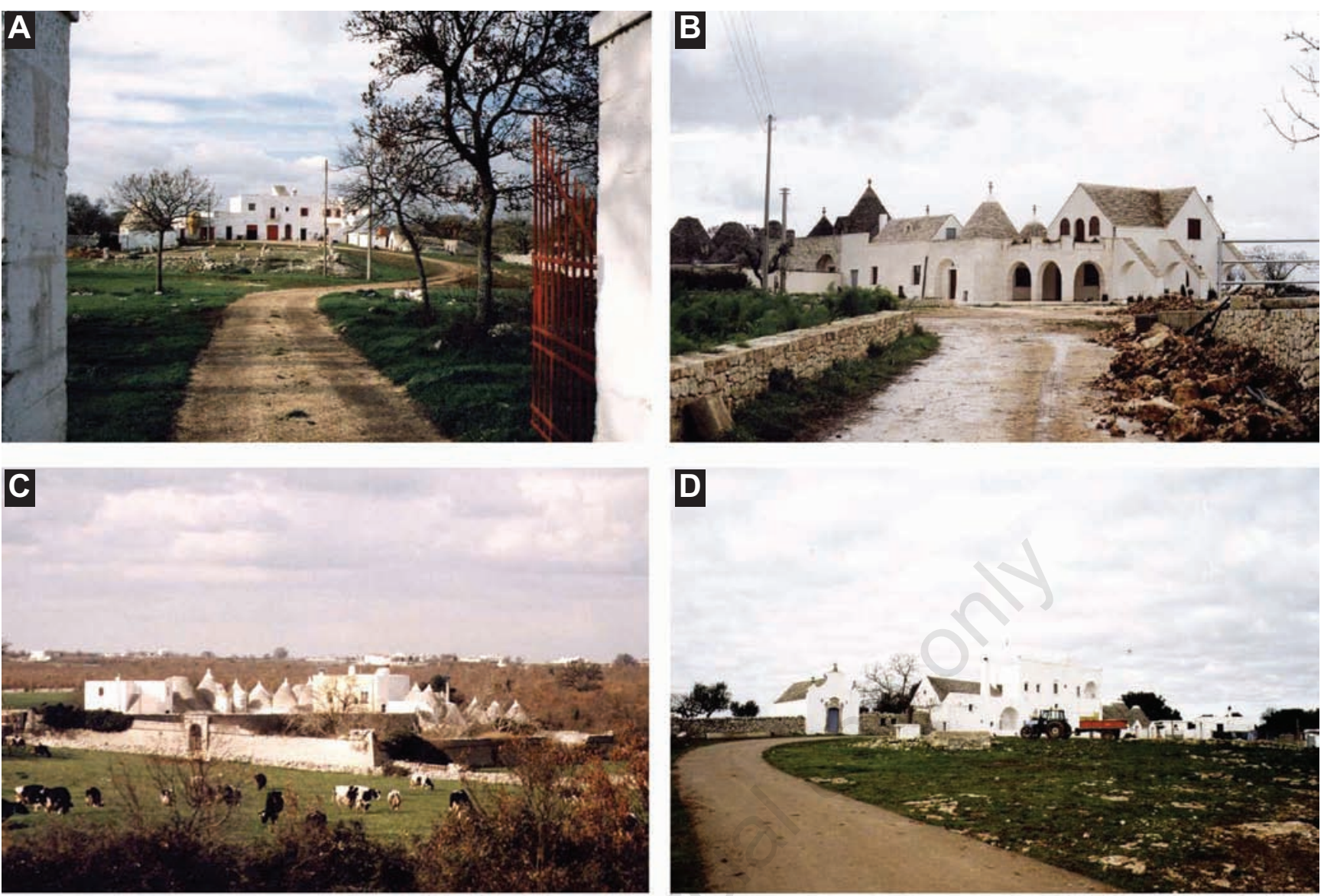

\section{D}

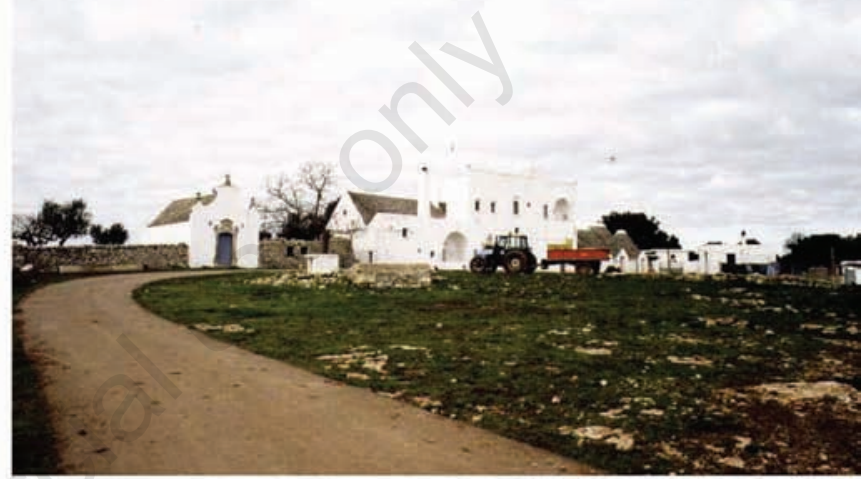

目

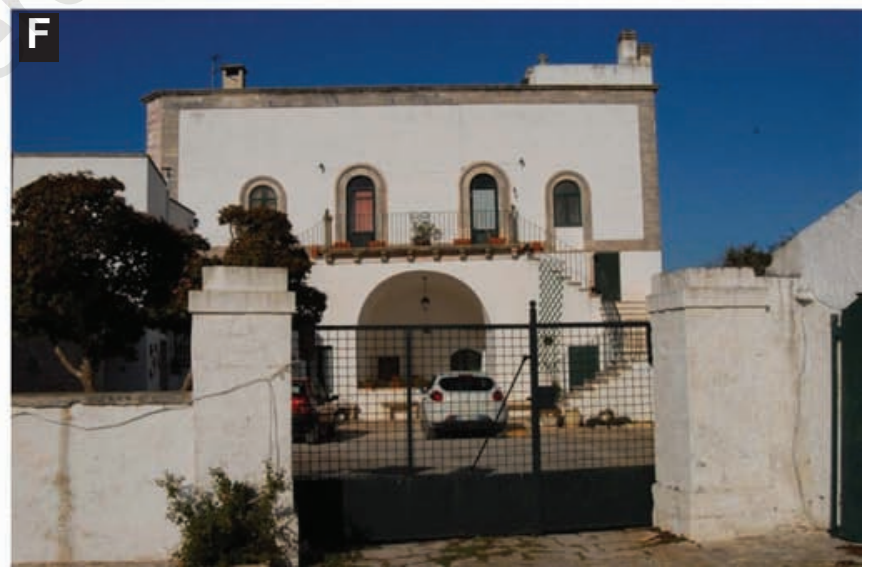

Figure 5. Masserie located in Martina Franca countryside: A) Motolese Murge; B) Paglierona; C) Croce Grande; D) Cavaliere; E) Gorgo; F) Carrucola.

\section{References}

Aromatario M.M. 1986. [Director of the transhumance and of the Samnites cultures]. In: Touring Club Italiano (eds.), Itinerari turistico-culturali del Mezzogiorno d'Italia. Mondadori, Milano, Italy, pp 69-80 [In Italian].

Calderazzi A. 1989. L'architettura rurale in Puglia: le masserie. Schena, Fasano (BR), Italy.
Caliandro L.P., Dal Sasso P. 2012. Drawing the old agro-industrial landscape in Puglia: a case study to promote the rural sustainable development. In: R. Amoêda, S. Lira, C. Pinheiro (eds.), Heritage 2012: Proceedings of the 3rd International Conference on Heritage and Sustainable Development, 2012 June 19-22, Porto, Portugal. Green Lines Institute for Sustainable Development, Barcelos, Portugal, pp 1075-86.

Ciacio N. 1986. [Director of the Appia Antica.] In: Touring Club Italiano (eds.), Itinerari turistico-culturali del Mezzogiorno d'Italia. 
Mondadori, Milano, Italy, pp 33-42 [In Italian].

Cippone N. 1993. La Via Appia e la terra jonica. Nuova Editrice Apulia, Martina Franca (TA), Italy.

Council of Europe. 2000. European landscape convention. 2000. Available from: http:/www.coe.int/EuropeanLandscapeConvention Accessed: January 2013.

Council of Europe. 2005. Council of Europe framework convention on the value of cultural heritage for society. Available from:http://conventions.coe.int/Treaty/en/Treaties/Htm/199.htm Accessed: January 2012.

Colamonico C. 1970. La casa rurale nella Puglia. Olschki, Firenze, Italy.

Colapietra R. 1985. I grandi tratturi nella tematica attuale dei beni ambientali. In: Proc. 4th Congress on Prehistory - Proto-history History of Daunia. Civica Amministrazione-Biblioteca Comunale A. Minuziano-Archeoclub d'Italia, San Severo (FG), Italy, pp 202-272.

Dal Sasso P., Caliandro L.P. 2010. The role of agro-industrial buildings in the study of rural territory. Landscape Urban Plan 96:146-62.

Dal Sasso P., Caliandro L.P., Ottolino M.A., Loisi R.V. 2010. Il ruolo delle risorse territoriali nell'individuazione di greenway. In: P. Dal Sasso (ed.), Il paesaggio nell'analisi e pianificazione del territorio rurale. Grenzi, Foggia, Italy, pp 83-103.

Dal Sasso P., Marinelli G., Ottolino A. 2004. Una rete di percorsi verdi per lo sviluppo e la valorizzazione del Gargano Nord. In: P. Dal Sasso, A. Galli, V. Mennella, A. Toccolini (eds.), Greenway per lo sviluppo sostenibile del territorio. Il Verde Editoriale, Milano, Italy, pp 189-243.

Dal Sasso P., Ottolino A., Loisi R.V. 2009. Masserie di Puglia: censimento e analisi delle tipologie. Estimo Terr. II:42-54.

European Commission. 1998. First framework programme in support of culture (2000-2004) - COM (1998) 266. Commission of the European Communities, Brussel, Belgium.

European Commission. 2006. EU rural development policy 2007-2013. Office for official Publications of the European Communities, Luxembourg, Luxembourg.

Fuzio G. 1974. Masserie fortificate di Puglia. In: R. De Vita (ed.), Castelli, torri ed opere fortificate di Puglia. Adda, Bari, Italy.

Hassler U., Algreen-Ussing G., Kohler N. 2002. Cultural heritage and sustainable development in SUIT. SUIT Position Paper, 3. Available from: http://www.lema.ulg.ac.be/research/suit/Reports Accessed: December 2011.

Hudson J.A. 1975. A location theory for rural settlement. In: R.L. Singh (ed.), Readings in rural settlement geography. Tara Printing Works, Kamacha, India, pp 103-21.

Italian Regulation. 1912. Elenco dei tratturi, tratturelli, bracci e riposi del Tavoliere delle Puglie. In: Official Journal No. 97, 23/04/1912, available from: http://augusto.digitpa.gov.it/gazzette/index/download/id/1912097_PM

Jurick J. 2006. A spatial analysis of the early settlement of Somerset County, Pennsylvania. Penn Geogr. 44:17-38.

Licinio R. 1981. L'organizzazione del territorio fra XIII e XV secolo. In: D. Blasi (ed.), La Puglia tra Medioevo ed Età moderna. Città e campagna. Electa, Milano, Italy, pp 329-336.

Lynch K. 1960. The image of the city. The MIT Press, Cambridge, MA.

Ministero dell'Ambiente. 2004. I territori della transumanza: una rete per i parchi (a cura di A. Busca, B. Di Rico, V. Fabietti). Dierre Edizioni, San Salvo (CH), Italy.

Otranto G. 2007. Cento itinerari più uno in Puglia. Gelsorosso, Bari, Italy.

Palasciano I. 1999. Le lunghe vie erbose: tratturi e pastori del Sud. Capone, Cavallino di Lecce (LE), Italy.

Pašakarnis G., Maliene V. 2010. Towards sustainable development in Central and Eastern Europe: applying land consolidation. Land Use Policy 27:545-49.

Spooner P.G. 2005. On squatters, settlers and early surveyors: historical development of country road reserves in southern New South Wales. Aust Geogr. 36:55-73.

Tragni B. 1986. Itinerari turistico-culturali in Puglia: le vie della transumanza. Adda, Bari, Italy.

Tweed C., Sutherland M. 2007. Built cultural heritage and sustainable urban development. Landscape Urban Plan 83:62-9.

Van der Vaat J.H.P. 2005. Towards a new rural landscape: consequences of non-agricultural re-use of redundant farm buildings in Friesland. Landscape Urban Plan 70:143-52. 